\title{
Hubungan Nutrien Pada Sedimen dan Penutupan Lamun Di Perairan Jepara
}

\author{
Sarah Nabilla*, Retno Hartati dan Ria Azizah Tri Nuraini \\ Departemen IImu Kelautan, Fakultas Perikanan dan IImu Kelautan, Universitas Diponegoro \\ JI. Prof. H. Soedharto, SH., Tembalang, Semarang, Indonesia 50275 \\ Email: nabillasarahpilli@gmail.com
}

\section{Abstract \\ Relationship between Nutrients in Sediments with Seagrass Coverage in Jepara Waters}

The availability of nutrients in seagrass beds can act as growth limiting factors. Absorption of nutrients in the water column is carried out by the leaves while the absorption of nutrients from the sediment is carried out by the roots but does not rule out the transport of nutrients by the roots will also arrive at the leaves of the seagrass. If the nutrient requirement is not met properly, then the growth will be disrupted. Like the difference in distribution and density of seagrass itself. Nutrient concentrations in waters vary. Nitrate and phosphate levels in the waters are strongly influenced by sources of organic material from outside/land (allochthonous) or from the water itself (autocthonous). This research was conducted with the aim of nothing: to determine the relationship between nutrient content (nitrate and phosphate) in sediment to seagrass cover in Teluk Awur and Pantai Blebak, JeparaData collection of seagrass and sediment was carried out on March 2018 in the waters of Teluk Awur and Blebak Beach, Kabupaten Jepara. Type identification, density, and coverage are carried out at the research location. Nitrate and phosphate analysis in sediments is carried out in Laboratorium Pengujian dan Peralatan. Based on the results of research that has been carried out, it can be concluded that there is a very strong positive relationship between nutrients and seagrass closure in the two research locations, each of which is 0.955 (91.1\%) in Teluk Awur waters and 0.962 (92.6\%) in Blebak Beach.

Keywords : Nutriens; Sediment; Nitrate; Phospate; Coverage

\begin{abstract}
Abstrak
Ketersediaan nutrien di perairan padang lamun dapat berperan sebagai faktor pembatas pertumbuhan. Penyerapan nutrien pada lamun pada kolom air dilakukan oleh daun sedangkan penyerapan nutrien dari sedimen dilakukan oleh akar namun tidak menutup kemungkinan pengangkutan nutrien oleh akar juga akan sampai pada bagian daun. Jika kebutuhan nutrien tidak terpenuhi dengan baik, maka pertumbuhannya mengalami gangguan. Seperti perbedaan sebaran dan kepadatan lamun itu sendiri. Konsentrasi nutrien di perairan bervariasi. Kadar nitrat dan fosfat di perairan sangat dipengaruhi oleh sumber bahan organik yang berasal dari luar/ daratan (allochthonous) maupun dari dalam perairan itu sendiri (autocthonous). Penelitian ini dilakukan dengan tujuan: untuk mengetahui hubungan antara kandungan nutrien (nitrat dan fosfat) pada sedimen terhadap tutupan lamun di Teluk Awur dan Pantai Blebak, Jepara. Identifikasi jenis, kepadatan dan penutupan dilakukan pada lokasi penelitian. Analisa nitrat dan fosfat dalam sedimen dilakukan di Laboratorium Pengujian dan Peralatan. Berdasarkan hasil penelitian yang telah dilakukan dapat di ambil kesimpulan bahwa terdapat hubungan sangat kuat positif antara nutrien dengan penutupan lamun pada dua lokasi penelitian, nilainya masingmasing sebesar 0,955 (91,1\%) di Perairan Teluk Awur dan 0,962 (92,6\%) di Pantai Blebak.
\end{abstract}

Kata kunci : Nutrien; Sedimen; Nitrat; Fosfat; Tutupan

*) Corresponding author

www.ejournal2.undip.ac.id/index.php/jkt
Diterima/Received : 25-01-2019, Disetujui/Accepted : 27-02-2019 DOI: https://doi.org/10.14710/jkt.v22i1.4252 


\section{PENDAHULUAN}

Fungsi dan manfaat padang lamun di ekosistem perairan dangkal adalah sebagai produsen primer, habitat biota, stabilisator dasar perairan, penangkap sedimen dan pendaur hara. Sebagai tumbuhan autotrofik, lamun mengikat karbondioksida $\left(\mathrm{CO}_{2}\right)$ dan mengubahnya menjadi energi yang sebagian besar memasuki rantai makanan, baik melalui pemangsaan langsung oleh herbivora maupun melalui dekomposisi sebagai serasah. Produktivitas primer padang lamun relatif tinggi di pesisir (Hernawan et al., 2017). Selain itu, rimpang dan akar lamun dapat menahan dan mengikat sedimen, sehingga dapat menguatkan dan menstabilkan dasar permukaan. Ketersediaan nutrien di perairan padang lamun dapat berperan sebagai faktor pembatas pertumbuhan sehingga efesiensi daur nutrisi dalam sistemnya akan menjadi sangat penting untuk melihat produktivitas primer padang lamun dan organisme autrotofnya (Hillman et al., 1989). Menurut Fachrul (2005), nitrat dan fosfat merupakan zat hara yang berperan penting dalam pertumbuhan dan metabolisme tumbuhan dan merupakan indikator untuk kualitas dan kesuburan suatu perairan.

Penelitian yang telah dilakukan oleh Riniatsih (2016) mengkaji tentang distribusi jenis lamun yang dihubungkan dengan sebaran nutrien perairan di Teluk Awur, Jepara. Hasilnya menujukkan sebaran lamun jenis Thalasisia hemprichii dan Enhalus acoroides cenderung menyebar pada habitat dengan substrat pasir berlumpur dengan kandungan bahan organik yang relatif tinggi. Sedangkan lamun jenis Cymodocea serrulata dan Syringodium isoetifolium lebih banyak ditemukan di habitat dengan substrat pasir halus. Pemanfaatan lahan di sekitar pesisir Kabupaten Jepara telah mengalami peningkatan pada kawasan terbangun, contohnya untuk pelabuhan, pariwisata dan permukiman. Sehingga limbah yang berasal dari kegiatan tersebut menimbulkan adanya perbedaan sumber nutrient. Teluk Awur memiliki karakteristik teluk dengan gelombang yang tidak begitu besar. Secara umum memiliki dasar perairan berupa pasir dan pecahan karang serta cangkang organisme laut. Pada bagian tepi banyak rumput laut dan lamun yang tumbuh. Pada bagian garis pantai terdapat ekosistem mangrove didominasi jenis Rhizopora sp, dan terdapat muara (Sunarernanda et al., 2014). Sedangkan Pantai Blebak memiliki kondisi lingkungan gelombang yang relatif kecil dan arus yang tenang. Menurut BPMPPT Kab. Jepara (2012), Pantai Blebak merupakan salah satu kawasan tambak udang. Letak tambak udang vannamei sangat berdekatan dengan pantai. Perbedaan karakteristik lingkungan antara Teluk Awur dan Pantai Blebak akan menyebabkan perbedaan sumber nutrien yang masuk pada perairan. Untuk itu perlu dilakukan penelitian ini dengan tujuan untuk :mengetahui mengetahui hubungan antara kandungan nutrien (nitrat dan fosfat) pada sedimen terhadap tutupan lamun di Teluk Awur dan Pantai Blebak, Jepara. Tujuan dilakukann mengetahui hubungan antara kandungan nutrien (nitrat dan fosfat) pada sedimen. mengidentifikasi jenis, kepadatan dan penutupan dilakukan pada lokasi penelitian.

\section{MATERI DAN METODE}

Materi yang digunakan pada penelitian ini adalah sampel sedimen untuk analisis nitrat, fosfat dan analisa ukuran butir serta lamun yang meliputi; Identifikasi jenis, kepadatan dan penutupan lamun. Penentuan lokasi penelitian menggunakan teknik pengambilan purposive sampling. Gambar 1 menunjukkan lokasi penelitian di Teluk Awur (gambar kiri) dan Pantai Blebak. Terdapat 4 stasiun pengamatan di setiap lokasi berdasarkan penutupan lamun yaitu; padat, sedang, sedikit dan tidak ada. Pengambilan sedimen menggunakan core dari pipa paralon berukuran jari-jari $5 \mathrm{~cm}$ dan panjang $30 \mathrm{~cm}$. kemudian core ditancapkan pada kedalaman $10 \mathrm{~cm}$ (metode core sampling) kemudian substrat yang didapatkan disimpan dalam ziplock dan diberi penanda untuk analisa butir sedimen (SB) dan kandungan nutrien (SN). Sampel SB tidak diperlakukan penyimpanan khusus sedangkan sampel SN disimpan pada coolbox selama perjalanan menuju laboratorium. Sampel SN dianalisa lebih lanjut di laboratorium untuk menetukan analisis 
kadar nitrat (SNI 06-6989.31-2005) dan fosfat (BP2-MU-A-08) dengan metode spektrofotometri.

Lamun diidentifikasi jenis, kepadatan, dan pengukuran penutupan. Pengamatan dilakukan dengan cara snorkeling pada transek kuadrat ukran $1 \times 1 \mathrm{~m}$ kemudian di catat identifikasi, jumlah tegakan dan penutupan. Acuan yang digunakan untuk identifikasi jenis lamun menggunakan buku Status Padang Lamun (Rahmawati et al., 2014). Parameter fisika-kimia yang diukur yaitu, salinitas, suhu, $\mathrm{pH}$, Oksigen Terlarut (DO), kecerahan dan kecepatan arus. Pengukuran parameter tersebut dilakukan dengan pengulangan sebanyak 3 kali, secara in-situ setiap stasiun.

Jumlah total individu suatu jenis lamun dalam unit luasan yang dihitung dengan menggunakan rumus (English et al., 1997). Perhitungan penutupan lamun dengan melihat nilai penutupan lamun di setiap kotak pada kuadrat. Dengan menjumlahkan seluruh nilai penutupan lamun pada seluruh kuadrat dengan menggunakan rumus (Rahmawati et al., 2014). Nilai penutupan lamun tersebut kemudian di kategorikan menurut Rahmawati et al., 2014 (Tabel 1). Hubungan antara kandungan nutrien dengan penutupan lamun dilakukan uji korelasi dengan menggunakan software SPSS. Analisis korelasi adalah suatu bentuk analisis data yang bertujuan untuk mengetahui kekuatan, bentuk arah hubungan antara dua variabel, dan besarnya pengaruh yang disebabkan oleh variabel bebas terhadap variabel terikat (Siregar, 2014).

Tabel 1. Kategori Penutupan Lamun

\begin{tabular}{cc}
\hline Penutupan (\%) & Kategori \\
\hline $0-25$ & Jarang \\
$26-50$ & Sedang \\
$51-75$ & Padat \\
$76-100$ & Sangat Padat \\
\hline
\end{tabular}

\section{HASIL DAN PEMBAHASAN}

Hasil pengukuran nitrat yang terkandung dalam sedimen pada perairan Teluk Awur diketahui berkisar 0,0397-0,67 ppm dengan rata-rata 0,341 ppm sedangkan di Pantai Blebak berkisar 0,273-0,821 ppm dengan rata-rata 0,539 ppm (Gambar 2). Terdapat perbedaan kandungan nitrat antara dua lokasi penelitian. Tingginya kandungan nitrat di Pantai Blebak dipengaruhi oleh buangan tambak dan pertanian serta lokasi ini yang sudah menjadi kawasan wisata pantai. Sehingga terdapat fasilitas yang memungkinkan menjadi sumber nutrien lain seperti toilet. Sedangkan di Teluk Awur, nutrien hanya berasal dari dekomposisi organisme mangrove berupa serasah. Hal ini didukung oleh Makmur (2012) menerangkan bahwa, sumber utama nitrat berasal dari buangan rumah tangga dan pertanian termasuk kotoran hewan dan manusia. Selain itu sumber nitrat di perairan juga berasal dari limbah yang mengandung senyawa nitrat berupa bahan organik dan senyawa anorganik seperti pupuk nitrogen, masukkan air tawar dari sungai.

Hasil pengukuran nitrat yang terkandung dalam sedimen pada perairan Teluk Awur diketahui berkisar 0,137-0,675 ppm dengan rata-rata 0,395 ppm sedangkan di Pantai Blebak berkisar 0-0,165 ppm dengan rata-rata 0,1186 ppm (Gambar 2). Terdapat perbedaan kandungan fosfat antara dua lokasi penelitian. Kandungan fosfat di Teluk Awur lebih tinggi dibandingkan Pantai Blebak. Kadar fosfat dalam sedimen lebih tinggi dibandingkan dalam air karena pada sedimen, fosfat akan terendapkan. Kadar fosfat yang ditemukan disebabkan oleh kondisi lingkungan pada masing-masing lokasi. Kandungan fosfat lebih rendah dibandingkan nitrat, karena fosfat merupakan faktor pembatas hal ini didukung oleh Smith (1984) menjelaskan bahwa, ketersediaan $P$ dianggap makronutrien yang berpengaruh terhadap laju produktivitas suatu perairan atau disebut pula sebagai faktor pembatas. Tingginya kandungan fosfat pada Perairan Teluk Awur dibandingkan dengan Pantai Blebak diduga karena penebangan hutan mangrove yang akan dijadikan tambak, sehingga terjadi peningkatan kadar fosfat.

Kepadatan lamun tertinggi di Teluk Awur terdapat pada Stasiun 1 dengan ratarata sebesar 69,5 tegakan $/ \mathrm{m}^{2}$. Kepadatan 
terendah di temukan pada Stasiun 3 dengan rata-rata sebesar 30 tegakan/m². Pada Stasiun 2 kepadatan lamun termasuk sedang dengan rata-rata 54 tegakan $/ \mathrm{m}^{2}$. Kepadatan lamun Enhalus acoroides tinggi diduga karena karakteristik jenis substrat lumupur yang mendukung sehingga dapat tumbuh dan berkembang dengan optimal. Waycott et al. (2004) menyatakan bahwa Enhalus acoroides memiliki persebaran yang luas dan menyukai daerah teluk dan daerah yang banyak ditumbuhi mangrove. Perairan Teluk Awur khususnya lokasi Stasiun berdekatan dengan tumbuhan mangrove. Kepadatan lamun tertinggi di Pantai Blebak terdapat pada Stasiun 1 dengan rata-rata sebesar 338 tegakan $/ \mathrm{m}^{2}$. Kepadatan terendah di temukan pada Stasiun 3 dengan rata-rata sebesar 39,5 tegakan $/ \mathrm{m}^{2}$. Pada Stasiun 2 kepadatan lamun termasuk sedang dengan rata-rata 120 tegakan/m². Kepadatan lamun Cymodocea serrulata tinggi bersubstrat pasir.

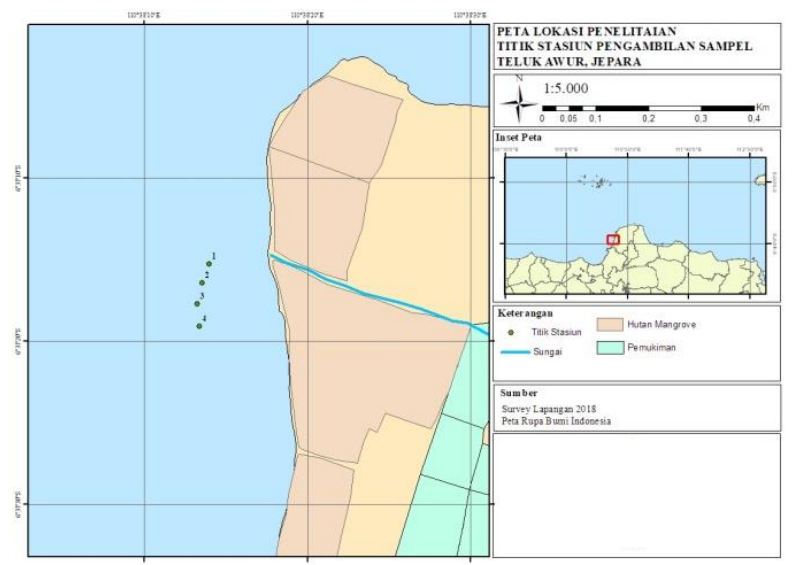

Teluk Awur
Diduga jenis substrat pasir merupakan daerah yang disukai lamun jenis tersebut untuk hidup. Sesuai dengan pernyataan Yunitha et al., (2014) bahwa jenis lamun Cymodocea serrulata mampu hidup pada sedimen jenis pasir.

Persentase tutupan lamun tertinggi di Teluk Awur terdapat pada Stasiun 1 dengan rata-rata sebesar $51,395 \%$. Persentase terendah di temukan pada Stasiun 3 dengan rata-rata sebesar $16,562 \%$. Pada Stasiun 2 Persentase tutupan lamun termasuk sedang dengan rata-rata $16,562 \%$. Persentase tutupan lamun tertinggi di Pantai Blebak terdapat pada Stasiun 1 dengan rata-rata sebesar $91,875 \%$. Persentase terendah di temukan pada Stasiun 3 dengan rata-rata sebesar 14,062\%. Pada Stasiun 2 Persentase tutupan lamun termasuk sedang dengan rata-rata 39,218\% (Gambar 4).

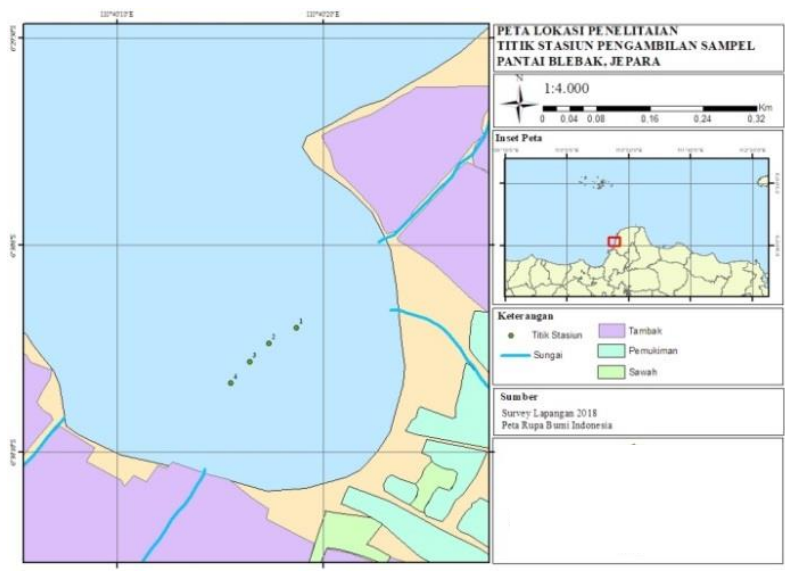

Pantai Blebak

Gambar 1. Peta Lokasi Penelitian
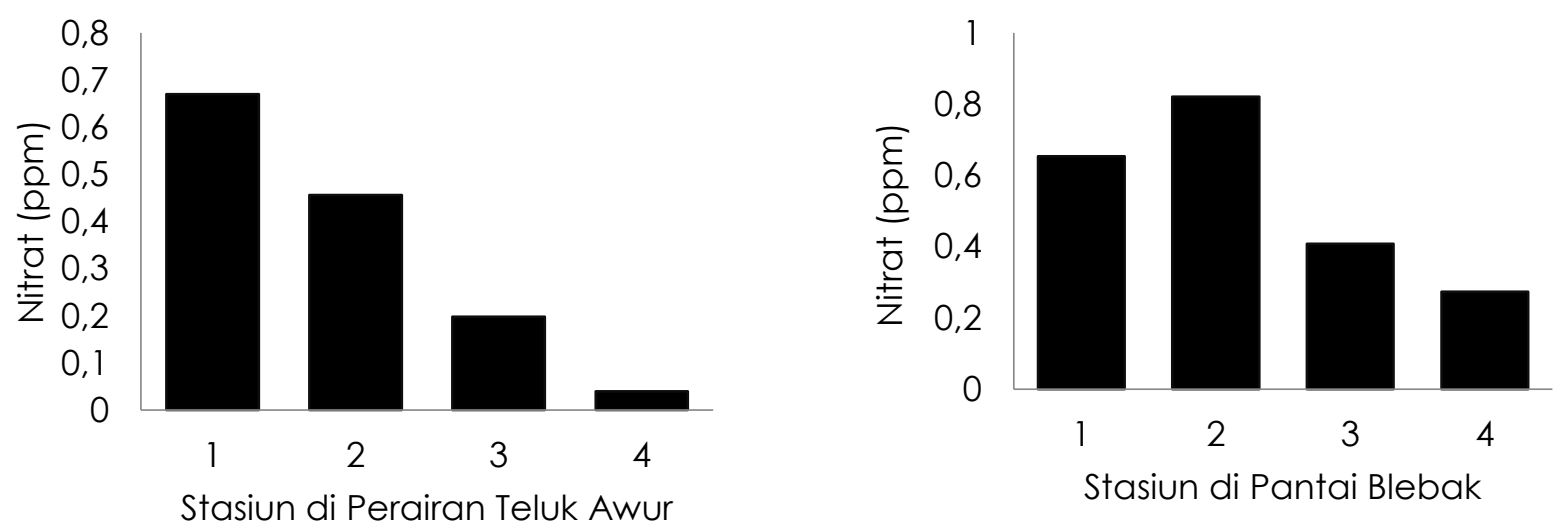

Gambar 2. Kandungan Nitrat pada Sedimen 

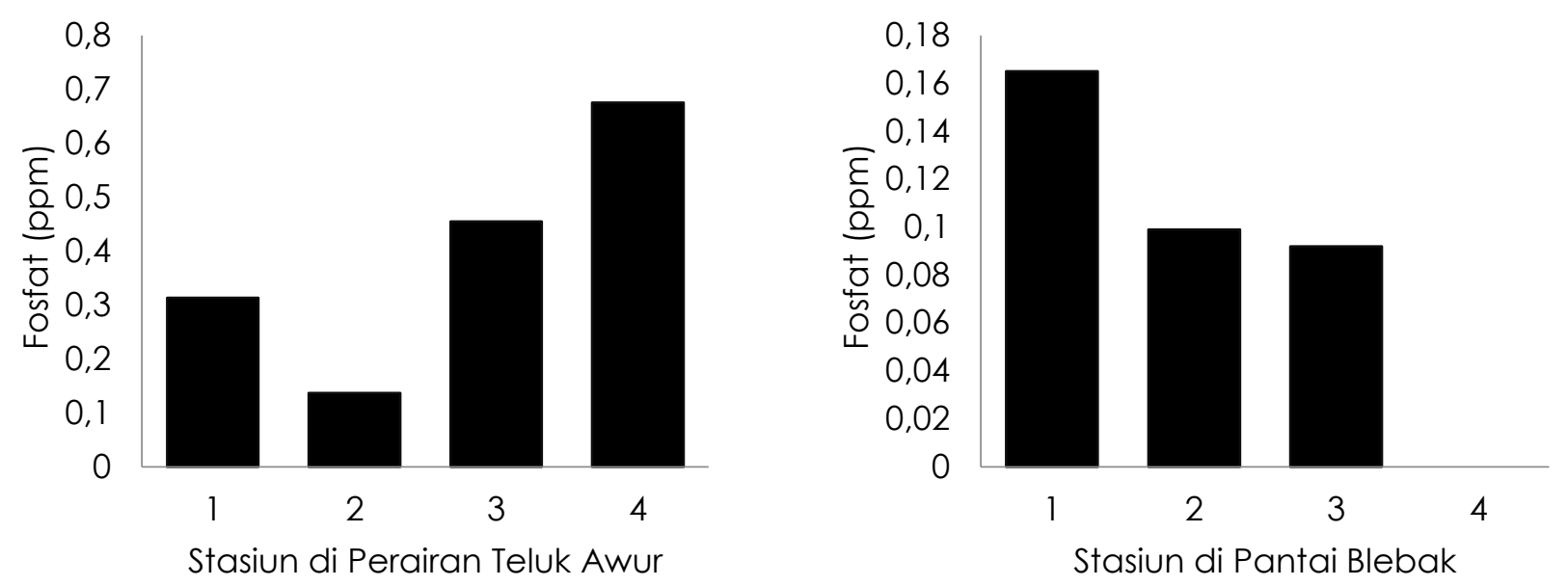

Gambar 3. Kandungan Fosfat pada Sedimen

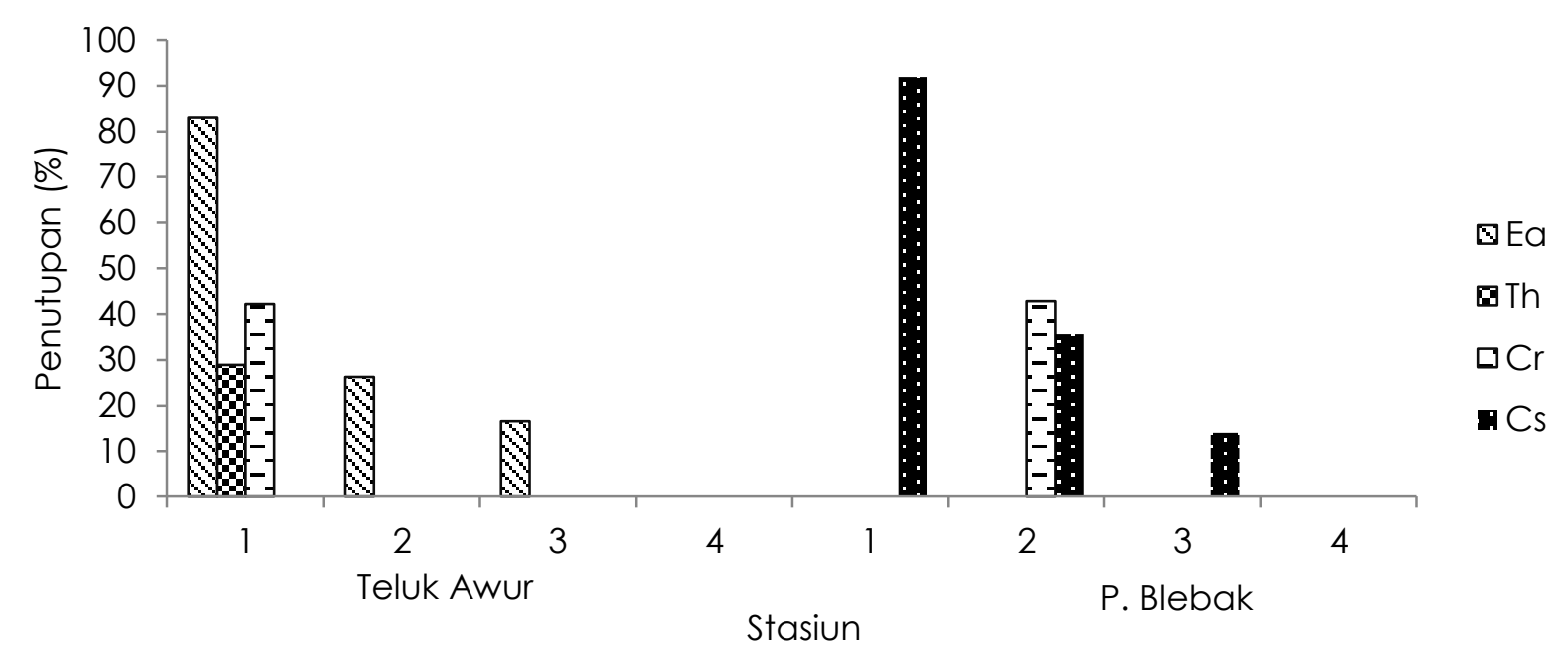

Gambar 4. Tingkat Penutupan lamun di perairan Teluk Awur dan Pantai Blebak

Tingginya persentase penutupan lamun pada masing-masing Stasiun 1 dari perairan Teluk Awur dan Pantai Blebak dipengaruhi oleh kepadatan jenis lamun pada Stasiun tersebut. Stasiun 1 pada perairan Teluk Awur terdapat lamun jenis Enhalus acoroides yang memberi pengaruh terhadap persentase tutupan. Demikian halnya dengan penelitian lain yang dilakukan oleh Hartati, et al. (2017) dan Riniatsih, et al. (2018) pada lokasi Ujung Piring, Jepara menyatakan bahwa Enhalus acoroides memiliki nilai tutupan tertinggi sebesar $48,67 \%$. Hal tersebut dapat terjadi karena spesies ini umumnya ditemukan tumbuh pada substrat berlumpur di perairan yang keruh, dapat membentuk spesies tunggal serta dapat mendominasi komunitas padang lamun (Short dan Coles, 2001). Sedangkan pada Pantai Blebak tingginya kepadatan lamun jenis Cymodocea serrulata memberi pengaruh lebih besar terhadap persentase tutupan. Persentase tutupan pada masing-masing Stasiun 1 jauh lebih tinggi dibandingkan dengan Stasiun 2 dan 3. Kerapatan yang tinggi dan kondisi pasang surut saat pengamatan mempengaruhi nilai persentase tutupan lamun (Handayani et al., 2016).

\section{Hubungan Kandungan Nutrien dalam sedimen dengan Penutupan Lamun}

Terdapat hubungan sangat kuat positif antara nutrien ( $\mathrm{N}$ dan $\mathrm{P}$ ) dengan penutupan 
lamun sebesar 0,955 (91,1\%). Pada Pantai Blebak terdapat hubungan kuat positif pula sebesar $0,962(92,6 \%)$. Hasil analisa tersebut menunjukan bahwa pada kedua lokasi kandungan nutrien berhubungan dengan penutupan lamun. Kedalaman substrat berperan dalam menjaga stabilitas sedimen, sebagai pelindung tanaman dari arus air laut, dan tempat pengolahan serta pemasok nutrien (Hartati et al., 2017). Nutrien ( $\mathrm{N}$ dan $\mathrm{P}$ ) berperan penting dalam pertumbuhan dan metabolisme fitoplankton termasuk tumbuhan autotrof. Kandungan nitrat dan fosfat suatu perairan dijadikan tolok ukur kesuburan perairan karena semakin optimal kandungan nitrat dan fosfat suatu perairan maka semakin melimpah terhadap pertumbuhan tumbuhan. (Mustofa, 2015).

\section{KESIMPULAN}

Berdasarkan hasil penelitian yang telah dilakukan dapat di ambil kesimpulan bahwa, perbedaan kandungan nutrien (nitrat dan fosfat) pada sedimen antara Teluk Awur dan Pantai Blebak menyebabkan perbedaan kondisi penutupan lamun di kedua lokasi tersebut. Terdapat hubungan kuat positif antara kandungan nutrien (nitrat dan fosfat) dengan penutupan lamun di Perairan Teluk Awur dan Pantai Blebak.

\section{DAFTAR PUSTAKA}

English, S., Wilkinson, C., \& Baker, V. 1997. Survey Manual for Tropical Marine Resources, 2nd Edition. Australian Institute of Marine Science Townsville

Fachrul, M., Haeruman, H. \& Sitepu, L.C. 2005. Komunitas Fitoplankton sebagai Bioindikator Kualitas Perairan Teluk Jakarta. Universitas Indonesia. Jakarta.

Handayani, D. R., Armid., \& Emiryati., 2016. Hubungan Kandungan Nutrien Dalamsubstrat Terhadap Kepadatan Lamun Di Perairan Desa Lalowaru Kecamatan Moramo Utara. J. Sapa Laut. $1(2): 42-53$

Hartati, R., Widianingsih, Santosa, A., Endrawati, H., Zaenuri, M., Riniatsih, I., Saputra, W.L., \& Mahendrajaya, R.T. 2017.Variasi Komposisi dan Kerapatan
Jenis Lamun di Perairan ujung Piring Kabupaten Jepara. J. Kel. Trop. 20(2):96105

Hernawan, U. E., Nurul, D. M. S., Indarto, H. S., Suyarso, Marindah, Y. I., Kasih, A., \& Rahmat. 2017. Status Padang Lamun Indonesia 2017. Puslit Oseanografi - LIPI. Jakarta

Hillman, K., D.J. Walker, A.W.D. Larkum, \& A.J. MC Comb. 1989. Productivity and Nutrients Limitation on Seagrasses. Biology of Seagrasses. Elsevier Science Publishers. Netherland

Makmur, M., H. Kusnoputranto., S.S. Moersidik. \& D. Wisnubroto.2012. Pengaruh Limbah Organik dan Rasio N/P terhadap Kelimpahan Fitoplankton di Kawasan Budidaya Kerang Hijau Cilincing. J. Teknol. Pengelolaan Limbah. 15(2):6-7

Mustofa, A. 2015. Kandungan Nitrat dan Pospat Sebagai Faktor Tingkat Kesuburan Perairan Pantai. J. DISPROTEK. Teknologi UNISNU Jepara 6(1):13-19

BPMPPT Kab. Jepara. 2012. Profil Investasi Kab. Jepara Tahun 2012. Kab. Jepara

Rahmawati, S., Andri, I., Indarto, H.S., \& Muhammad, H.A. 2014. Panduan Monitoring Lamun. CORE-MAP LIPI. Jakarta

Riniatsih, I. 2016. Distribusi Jenis Lamun Dihubungkan dengan Sebaran Nutrien Perairan di Padang Lamun Teluk Awur Jepara. J. Kel. Trop. 19(2):101-107

Riniatsih, I., Hartati, R., Rejeki, S. \& Endrawati, H. 2018. Studi Keanekaragaman Makrozoobentos Pada Habitat Lamun HasilT ransplantasi dengan Metode Ramah Lingkungan. J. Kel. Trop. 21 (1):2936

Short, F.T. \& Coles, R.G. 2001. Global seagrass research methods. Elsevier, Amsterdam

Siregar, S. 2014. Statistik parameterik untuk penelitian kuantitatif: dilengkapi dengan perhitungan manual dan aplikasi SPSS versi 17. Edisi 1. Jakarta: Bumi Aksara

Smith, S.V. 1984. Phosphorus versus nitrogen limitation in the marine environment. Limnol. Oceanogr. 29: 1149-1160

Sunarernanda, Y.P., Ruswahyuni \& Suryanti. 2014. Hubungan Kerapatan Rumput Laut dengan Kelimpahan Epifauna pada Substrat Berbeda di Pantai Teluk Awur Jepara. Jurnal Maquares. 3(3):43-51 
Waycott, M., McMahon, K., Mellors, J., Calladine, A. \& Kleine, D. 2004. A Guide to Tropical Seagrasses of the Indo-West Pacific. James Cook University, Townsville $(\mathrm{AU})$.
Yunitha, Alphina., Yusli W., dan Fredinan Y. 2014. Diameter Substrat dan Jenis Lamun di Pesisir Bahoi Minahasa Utara: Sebuah Analisis Korelasi. J. Ilmu Pertanian Ind. 19(3):130-135. 